\title{
Prevalence of overweight and associated risk factors among primary female school children in Al-Ain city United Arab Emirates
}

\author{
Abdelhamid Kerkadi, Nassar Abo-Elnaga, and Wissam Ibrahim
}

Department of Nutrition and Health, College of Food and Agriculture, UAE University, UAE P.O Box 17555, Al Ain, UAE.

\begin{abstract}
Obesity is currently an escalating epidemic that affects many countries in the world including the Gulf region where this condition is responsible for an increasing death rates annually. The objective of the study was to evaluate the prevalence of overweight and associated risk factors in primary female school children in Al Ain city, United Arab Emirates (UAE). Height and weight were measured in a sample of 900 female primary school children aged between 5-14 years. Body Mass Index (BMI) was calculated for each child. Children were categorized according to age and specific percentile of BMI using 2000 CDC BMI-age growth charts. A questionnaire addressing food habits, food consumption and life style (TV watching and physical activity) was completed. The results showed that the prevalence of the risk of overweight and overweight were $11.1 \%$ and $15.8 \%$ respectively. Sixty percent of children consumed chips and chocolates daily while $28 \%$ and $32.2 \%$ reported a daily consumption of vegetables and fruits respectively. Viewing TV more than $2 \mathrm{~h} /$ day, parents obesity, breakfast intake and physical activity were significantly associated with a higher risk of overweight. Results indicated that a high prevalence of overweight exists among primary school female children. This calls for aggressive prevention strategies which, if successful, may significantly reduce adult obesity.
\end{abstract}

Key words: Overweight. Female school children, risk factors, Food consumption patterns.

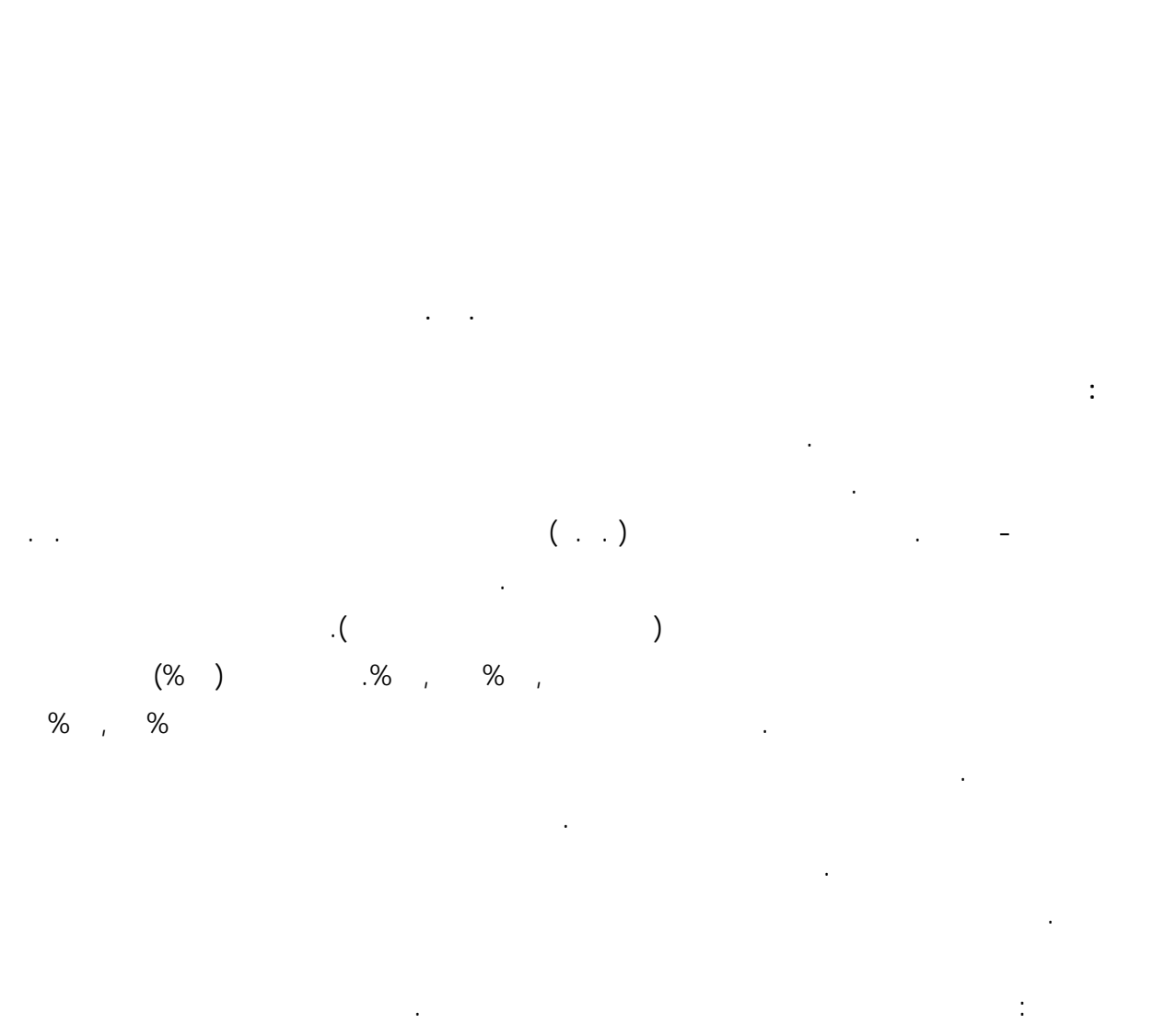




\section{Introduction}

Obesity is currently an escalating epidemic that affects many countries in the world including the Arabian Gulf region (Al-Awadi and Amine, 1989; AlShammari et al., 1994; El-Mugamer et al., 1995; Al-Mahroos and Al-Roomi, 1999) where it is responsible for increasing death rates annually. This condition could occur during any of the various stages of human life (Dietz, 1994).

Obesity among children is a concern, because it may have long term health consequences. In high-income countries, extensive evidence indicates that obesity during childhood is related to adult obesity (Rolland-Cachera et al., 1987; Serdula et al., 1993; Power et al., 1997; Guo and Chumlea, 1999; Wang and Popkin, 2000).

The causes of pediatric obesity have not been elucidated completely, although it is suspected that a complex interaction of genetic, environmental, and behavioural factors is responsible (Schonfeld-Warden and Waeden, 1997). Recent research suggests that aspects of diet composition, may play a role in overweight (Nguyen et al., 1996; Maffeis et al., 2000). Low physical activity rates are associated with obesity (Wolf et al., 1993; Obarzanek et al., 1994) and television viewing has been shown to be a significant risk factor for pediatric obesity, both cross-sectionally and prospectively (Klesges et al., 1993; Gortmaker et al., 1996; Hanley et al., 2000; Coon et al., 2001).

The rates of overweight and obesity are much higher in the Arabian Gulf populations, including children, compared to developed countries (AlAwadi and Amine, 1989; Al-Shammari et al., 1994; El-Mugamer et al., 1995; Al-Mahroos and Al-Roomi, 1999). This increase in the prevalence of obesity is due to life style changes (physical activity, leisure, and modernization) and nutrition transition which are in relation with changing economic, social, and health factors (Al Isa, 1999). It is well known that Arabian Gulf countries moved toward the higher fat and higher refined carbohydrates Western diet (Kim et al., 2000). Major dietary changes include a large increase in the consumption of fat and added sugar in the diet, and often a marked increase in animal food products which is contrasted with a fall in total cereal intake, vegetable, and fruits consumption (Popkin, 2001).

The objective of the study was to evaluate the prevalence of the risk of overweight, overweight, and associated behavioural risk factors including food habits, television viewing, and physical activity in primary female school children in Al Ain city, United Arab Emirates (UAE).

\section{Methods}

Subjects and sample size

This study was conducted during the months of March and April, 2003 in AlAin city, UAE on local female students attending primary public schools (grades one to six). According to the 2002-2003 statistics of the UAE Ministry of Education's, the total number of local children enrolled in Al-Ain primary public schools is 20,040 out of which 10,303 are female students.

A list of schools was obtained from the Ministry of Education and eight primary female schools were randomly selected from the list using a random number table. After that, two classes were selected from each grade in each of the eight schools. Then, a list of students was obtained for each class, students were listed according to alphabetical order, and a number was assigned to every student on the list. This was followed by random selection of the desired number of students from each grade. Each student had the same probability of being selected. If the 
selected student was absent, the next number on the list was picked. The total number of subjects that participated in this study was 900 children which is about $9 \%$ of the total number of female students $(10,303)$ in Al-Ain primary schools. The age range of children was 5-14 years.

\section{Data collection}

The UAE University approved the protocol of the study. The ministry of Education and the Ministry of Health (School Health Department) approved the performance of the survey in the selected schools. The survey was based on questionnaire sent home and collection of anthropometric data from participating children.

Standard techniques were adopted for obtaining anthropometric measurements. Subjects were weighed in light clothes and with no shoes using a seca scale at nearest $0.1 \mathrm{~kg}$. Height was measured to nearest $0.1 \mathrm{~cm}$ using a wall mounted stadiometer.

The Body Mass Index (BMI) was determined from the ratio of weight to height square. Children were categorized according to age and specific percentile of BMI using 2000 CDC BMI-age growth charts (Flegal et al., 2002; Mei et al., 2002). Underweight is defined as less than or equal to the age specific $5^{\text {th }}$ percentile. Normal weight is defined as between the $5^{\text {th }}$ and $85^{\text {th }}$ age-specific percentile. Students between the $85^{\text {th }}$ and $95^{\text {th }}$ are categorized as at risk of being overweight. At the $95^{\text {th }}$ percentile and above, children are classified as overweight.

Two questionnaires have been used to collect data. These questionnaires were pilot tested on one school prior to undertaking the study. During pilot testing, questionnaires underwent several modifications. The modified questionnaires were used to collect data. The first questionnaire, a self administrated questionnaire addressed to parents and sent with students along with a cover letter explaining the purpose of the study. The parents of each selected child were asked to complete the questionnaire and to send it with their children to school. The completed questionnaires were collected from the school head master by the researchers. The questionnaire consisted of two sections. A general section concerned family data such as marital status of parents, father and mother level of education, parents occupation, family size, and obesity within family. Parents were asked to describe themselves as obese or normal. The second section consisted a food frequency questionnaire which was developed by the Department of nutrition and Health, UAE University. Intake of foods were categorized as follows: Almost daily, once a week, 2-4 times per week, and none (less than once a week). Foods were divided in food groups: Fruits and fruit juice, vegetables, meat, dairy, bread and cereals. Three other food groups were also included: sweet and snacks, soft drink and beverage (tea, coffee). Sweet and snacks food included fast food, chips, cookies. Fast food consumption defined as foods consumed away from home in fast food restaurants. The second questionnaire administrated to students in the classroom by trained data collectors included questions related to behavioural factors such as the number of hours spent on watching television and video or playing video games the previous day. Almost all students reported watching television, for that, only this variable was used in the analysis. TV watching may vary from day to day. For that, TV watching was categorized in $0-2 \mathrm{~h} / \mathrm{d}$ or $>2 \mathrm{~h} / \mathrm{d}$. Students were asked to report if they were participating in physical activity and how much money did they bring daily with them to school. Pocket money was categorized in two levels: $[0-3 \mathrm{Dh} / \mathrm{d},>3$ $\mathrm{Dh} / \mathrm{d}](\mathrm{Dh}=$ Dirhams; $1 \$=3.678 \mathrm{Dh})$. The questionnaire asked about the consumption of snacks (defined as any 
food consumed excluding formal meals), while watching television, breakfast and number of meals intake.

\section{Statistic Analysis}

A database was set up using Microsoft Access to store the data. Then the data was read by SPSS (11.0) for windows which was used for statistical analysis.

Data analysis included both descriptive and inferential statistics. Correlation coefficients were calculated for the continuous variables (BMI, weight and height) to identify possible associations. The mean BMI, weight and height were tested by an analysis of variance (ANOVA) to assess differences between age groups. The percentage of the study population in different BMI categories was calculated for the total sample and stratified by age group. Multiple logistic regression was used to examine factors associated with overweight in the study population, including television viewing, breakfast intake, daily physical activity, pocket money and parents obesity. The outcome variable for these analyses was overweight defined as children with body mass index (BMI) greater or equal to the age-specific $85^{\text {th }}$ percentile of 2000 CDC growth charts. All variables were analyzed as a 2 level categorical variable: Television viewing [ $(0-2 \mathrm{~h} / \mathrm{d})$, $(>2 \mathrm{~h} / \mathrm{d})]$; daily physical activity [yes, no]; pocket money $[(0-3 \mathrm{Dh} / \mathrm{d})$, $(>3 \mathrm{Dh} / \mathrm{d})]$, breakfast intake [yes, no] and parents obesity [at least one of them, no]. Age was treated as potential confounding variable. Odds ratios (ORs) and their 95\% confidence intervals (CI) for associated factors were estimated from logistic regression models by exponentiating the $\beta$ coefficient. Food groups frequency of consumption was presented as daily frequency of consumption. Bivariate for testing between group variable differences were done using the independent $t$ test. The independent association of predictors (food groups) with overweight was also examined using multiple logistic regression adjusting for age. All food groups were included in the model. ORs were considered statistically significant at $P$ value $<0.05$.

\section{Results}

Among nine hundred girls initially included in the study, five hundreds forty five filled out the questionnaire and returned it to schools. We were unable to collect the remaining questionnaires because some parents did not want to participate in the study. In addition some parents did not complete all questions related to food consumption pattern, we were also unable to obtain anthropometric measures on 5 children. The reason for missing anthropometric measures was lack of time to finish anthropometry in some schools on scheduled days. $93-97 \%$ of children gave information on TV watching, physical activity, breakfast intake, pocket money, number of meals, and parents obesity. The demographic and socio-economic characteristics of the subjects are shown in Table 1. The mean age of participants was $9.4 \pm 1.8 \mathrm{y} .20 .8 \%$ of children lived in small families (5 persons or less). Fathers' education was higher than mothers' education. Only 12.2 $\%$ of mothers were employed. $6.7 \%$ of fathers and $12.2 \%$ of mothers were obese.

Anthropometric characteristics of the sample according to age are given in Table 2 . The study population was divided into 3 age groups as follows: group 1: 5-7 years; group 2: 8-10 years and group 3: 11 years and over. Results show that weight, height, and BMI increased with age and differences were significant $(P<0.0001)$ between age groups. A statistically significant $(P<0.001)$ positive correlation between age and anthropometric measurements was observed (Pearson Correlation was $0.586,0.740$ and 0.389 for weight, height, and BMI, respectively). 
Emir. J. Agric. Sci. 2005.17 (1): 43-56

http://www.cfa.uaeu.ac.ae/Research/EJAS.htm

Table 1. Demographic and socio economic characteristics of the sample

\begin{tabular}{|c|c|c|}
\hline Category & Number & $\%$ \\
\hline \multicolumn{3}{|l|}{ Age (years) } \\
\hline $5-7$ & 184 & 20.4 \\
\hline $8-10$ & 450 & 50.0 \\
\hline$\geq 11$ & 266 & 29.6 \\
\hline Total & 900 & \\
\hline \multicolumn{3}{|l|}{ Family size (persons) $^{\mathrm{a}}$} \\
\hline 5 or less & 114 & 20.8 \\
\hline $6-10$ & 298 & 54.5 \\
\hline$\geq 11$ & 135 & 24.7 \\
\hline Total & 547 & \\
\hline \multicolumn{3}{|l|}{ Mother education ${ }^{\mathrm{b}}$} \\
\hline 1 & 243 & 46.3 \\
\hline 2 & 206 & 39.2 \\
\hline 3 & 76 & 14.5 \\
\hline Total & 525 & \\
\hline \multicolumn{3}{|l|}{ Father education ${ }^{b}$} \\
\hline 1 & 165 & 32.2 \\
\hline 2 & 251 & 48.9 \\
\hline 3 & 97 & 18.9 \\
\hline Total & 513 & \\
\hline Mothers employed & 64 & 12.2 \\
\hline Fathers employed & 419 & 81.5 \\
\hline \multicolumn{3}{|l|}{ Parents obesity } \\
\hline Fathers & 60 & 06.7 \\
\hline Mothers & 110 & 12.2 \\
\hline Presence of house maid ${ }^{\mathrm{c}}$ & 433 & 82.5 \\
\hline
\end{tabular}

Table 2. Anthropometric characteristics of the sample according to age ${ }^{\text {a }}$

\begin{tabular}{lllll}
\hline Age groups & $\mathbf{N}^{\mathbf{b}}$ & Weight $\mathbf{( K g )}$ & Height $(\mathbf{c m})$ & BMI $^{\mathbf{c}}\left(\mathbf{K g} / \mathbf{m}^{2}\right)$ \\
\hline $5-7$ & 184 & $23.4 \pm 0.4^{*}$ & $122.4 \pm 0.5^{*}$ & $15.5 \pm 0.2^{*}$ \\
$8-10$ & 445 & $32.1 \pm 0.5^{*}$ & $133.3 \pm 0.4^{*}$ & $17.7 \pm 0.5^{*}$ \\
$\geq 11$ & 266 & $44.1 \pm 0.8^{*}$ & $146.2 \pm 0.5^{*}$ & $20.4 \pm 0.3^{*}$ \\
Total & 895 & $33.8 \pm 0.4$ & $134.9 \pm 0.4$ & $18.1 \pm 0.1$ \\
\hline
\end{tabular}

${ }^{a}$ Values are Mean \pm Standard Error (SE)

${ }^{\mathrm{b}} \mathrm{N}$ : Number of individuals

${ }^{c}$ BMI: Body Mass Index

* Significantly different between age groups at $P<0.0001$

The prevalence of underweight, normal weight, risk of overweight and overweight according to age is shown in Graph 1. Results show that $11.1 \%$ were at risk of overweight, $15.8 \%$ were overweight, $61.6 \%$ had a normal weight and $11.6 \%$ were underweight. The prevalence of risk overweight increased with age and reached its highest rate $(12.5 \%)$ at age 11 years and over. The same trend was noted for overweight where the highest rate $(21.2 \%)$ was observed in the oldest group (11 years and over). A significantly association was found between BMI and age groups $\left(\chi^{2}=23.89, P<0.001\right)$. 


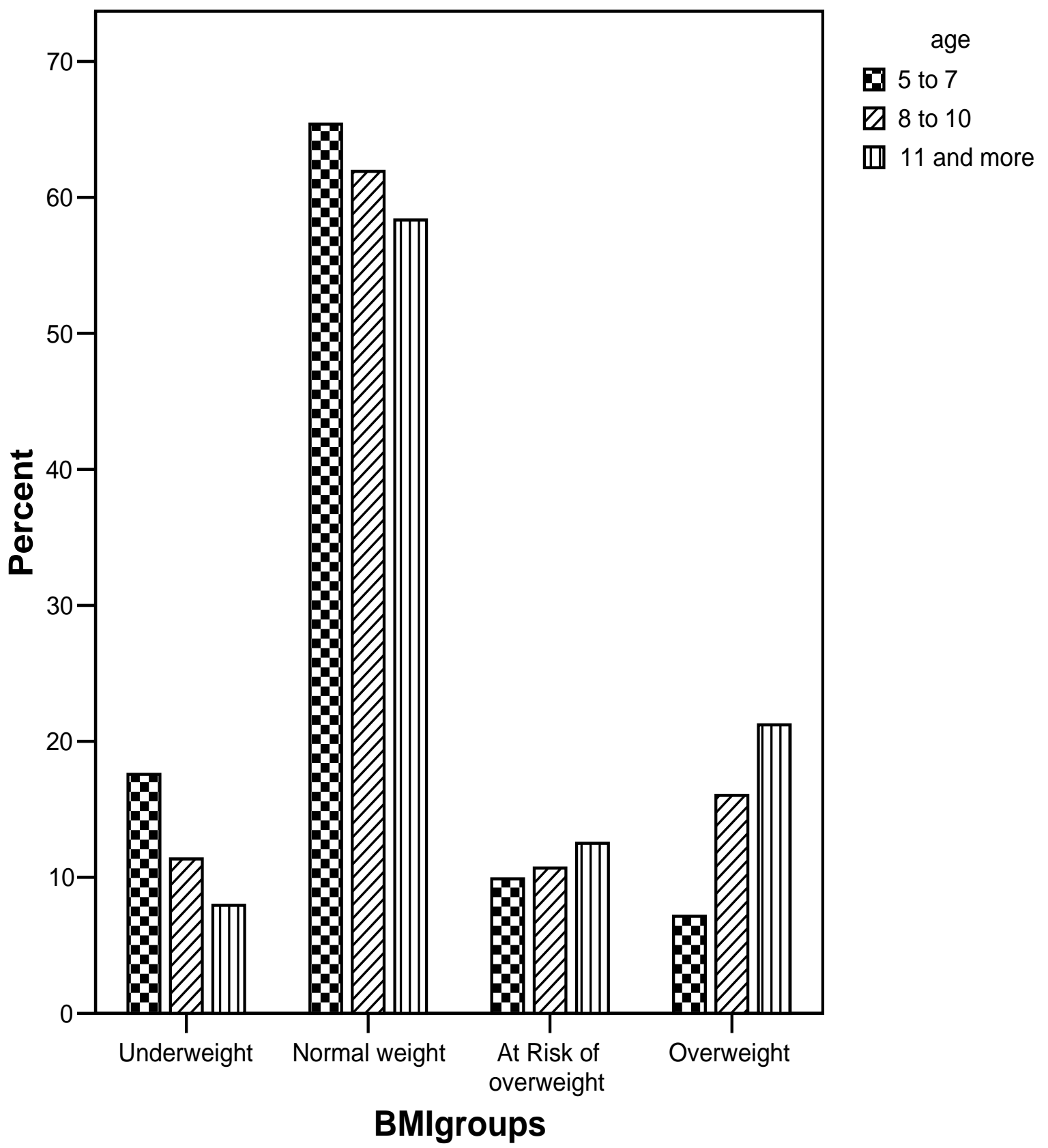

\section{Graph 1. Prevalence of underweight, normal weight, risk of overweight and

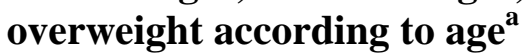

${ }^{\text {a }}$ Children were classified according to 2000 CDC BMI-age growth charts

* Significant difference according to age groups $, \chi^{2}=23.89, P<0.001$

Only five hundreds nineteen filled out the questionnaire related to food consumption frequency. It is noted that we did not find significant difference of anthropometric measurements (weight, height and BMI) between children who returned the questionnaire and children who did not return it. For that, the results of analysis of questionnaires can be considered as representative of the population. The analysis of the food consumption frequencies indicated that the consumption of fruits, leafy vegetables, and other vegetables was least frequent (32.2 \%, 28\% and $45.5 \%$ respectively). In addition, $38.8 \%$ and $18.8 \%$ of the subjects reported a daily consumption of chicken and meat respectively, while the daily 
consumption of fish was $13.2 \%$ (results not shown). The consumption of milk products was more frequent than full fat milk consumption (64\% versus $34.6 \%$ ). among cereals group, rice is the most frequently consumed food $(71.6 \%)$ followed by white bread (58.4\%) while $65.7 \%$ did not consume whole wheat bread (results not shown). We noted that $60.2 \%$ and $25.9 \%$ of children reported a daily consumed of chips and soft drink respectively, and $75 \%$ consumed fast food at least once a week. In addition, $37.3 \%$ of subjects reported a daily consumption of tea. $51.9 \%$ of children reported that they never snack while watching television (results not shown).

Table 3 shows comparison of food groups daily frequency of consumption between overweight and normal weight female primary school children. We noted that the daily frequency of consumption for all food groups did not differ between the two groups (overweight vs normal). Multiple logistic regression analysis was used to evaluate the association between daily frequency of food groups consumption (fruit, fruit juice, vegetables, bread and cereals, dairy, meat, sweets and snacks, soft drink and beverage) and overweight. All variables were included in the model after adjusting for age. Results shown that only the variable vegetables was marginally associated with overweight $(\mathrm{OR}=1.20 ; 95 \% \mathrm{CI}=0.995$ and $1.250 ; P$ $=0.056$ ).

Multiple logistic regression analyses indicated that breakfast intake, viewing TV more than 2hours/day, parent obesity, daily physical activity were positively associated with child overweight (Table 4). Girls who did not take breakfast were more likely to be overweight. There was a significant association between breakfast intake and overweight. Overall, $9.1 \%$ of girls reported watching 2 or more hours of television per day, $45.6 \%$ of them were overweight (results not shown). The prevalence of watching more than 2 hours of television per day increased with age and the maximum occurred in the oldest group (11 years and more) (results not shown). Compared with children who watched less than $2 \mathrm{~h} / \mathrm{d}$ of $\mathrm{TV}$, children who watched more than $2 \mathrm{~h} / \mathrm{d}$ had 2.88 greater OR (odds ratio) of being overweight. We noted a statistically significant association between watching 2 hours and more of television per day and overweight. $10.4 \%$ of girls did not practice sport, $40.2 \%$ of them were overweight and we noted that girls who did not practice sport were more likely to be overweight and the association between sport and overweight was statistically significant. $27.1 \%$ of children reported that they bring 3 and more Dh as pocket money per day and the totality was used to buy chips, candies and sandwich from the school's canteen. The prevalence of overweight children increased as the amount of pocket money increased (results not shown). We noted that students who bring $3 \mathrm{Dh}$ and more had 1.63 OR greater of being overweight and the association was not statistically significant at $P<0.05$. We did not find a significant association between pocket money and overweight because pocket money was correlated with age $(\mathrm{r}=$ $0.21, P=0.0001)$ and we adjusted for age in the multiple logistic regression model. Almost $26 \%$ of students have at least one of their parents obese and there was a significant association $(P=0.023)$ between parents obesity and child overweight. 
Table 3. Comparison of daily frequency of food consumption ${ }^{1}$ between overweight and normal female school children in Al-Ain city ${ }^{2}$

\begin{tabular}{llll}
\hline & Overweight $^{3}$ & Normal & P-value $^{4}$ \\
\hline $\mathrm{N}$ & 146 & 372 & \\
$\begin{array}{l}\text { Food groups } \\
\quad \text { Daily frequency }\end{array}$ & & \\
$\begin{array}{l}\text { Bread and cereals } \\
\text { Vegetables }\end{array}$ & $3.01 \pm 0.05$ & $3.01 \pm 0.04$ & 0.92 \\
Fruit & $3.17 \pm 0.10$ & $3.00 \pm 0.06$ & 0.12 \\
Fruit juices & $3.17 \pm 0.08$ & $3.16 \pm 0.05$ & 0.94 \\
Meat & $3.12 \pm 0.11$ & $3.15 \pm 0.07$ & 0.85 \\
Dairy & $2.69 \pm 0.05$ & $2.72 \pm 0.03$ & 0.64 \\
Sweets and snacks & $2.90 \pm 0.08$ & $2.92 \pm 0.05$ & 0.79 \\
Soft drinks & $2.95 \pm 0.07$ & $2.96 \pm 0.04$ & 0.96 \\
Beverage & $2.47 \pm 0.10$ & $2.50 \pm 0.06$ & 0.75 \\
\hline
\end{tabular}

*Values are means $\pm \mathrm{SE}$

${ }^{1}$ All age groups were included

${ }^{2}$ Overweight children are those with body mass index (BMI) greater or equal to the age-specific $85^{\text {th }}$ percentile of $2000 \mathrm{CDC}$ growth charts

${ }^{3}$ Student $t$ test

${ }^{4}$ Food groups: Breads and cereals: White bread, whole wheat bread, rice, pasta, breakfast cereals; Vegetables: leafy vegetables and other vegetables; fruit: apple, mango, peach, grapes, orange, banana; Fruit juices: fresh squeezed juices; Meat: beef, lamb, Chicken, fish and meat products; Dairy: milk (low fat and full fat), cheese, yogurt; Sweets and snacks: chocolate, chips, candy, cookies, popcorn; soft drinks: soft drinks, soda; Beverage: tea, coffee

Table 4. Factors associated with overweight ${ }^{1}$ in female school children* in Al Ain city. Multiple logistic regression ${ }^{2}$

\begin{tabular}{lllll}
\hline & \multirow{2}{*}{ OR $^{3}$} & \multicolumn{2}{c}{$\mathbf{9 5 \% \mathbf { C I } ^ { \mathbf { 4 } }}$} & \multirow{2}{*}{$\boldsymbol{P}$-value } \\
\cline { 3 - 4 } & & Lower & Upper & \\
\hline Breakfast Intake $^{5}$ & 1.82 & 1.31 & 2.53 & 0.0001 \\
${\text { TV viewing, } \mathrm{h} / \mathrm{d}^{6}}$ & 1.74 & 1.05 & 2.88 & 0.031 \\
Parents obesity $^{7}$ & 0.67 & 0.45 & 0.95 & 0.023 \\
Physical activity $^{8}$ & 1.58 & 0.94 & 2.57 & 0.06 \\
Pocket money $^{9}, \mathrm{Dh} / \mathrm{d}$ & 1.15 & 0.81 & 1.63 & 0.45 \\
\hline
\end{tabular}

* All age groups were included

${ }^{1}$ Overweight children are those with body mass index (BMI) greater or equal to the age-specific $85^{\text {th }}$ percentile of 2000 CDC growth charts

${ }^{2}$ Multiple logistic regression analysis was performed on group membership (overweight vs normal) as outcome and all five factors were included in the model after adjusting for age

${ }^{3} \mathrm{OR}=$ odds ratio

${ }^{4} 95 \% \mathrm{CI}=95 \%$ Confidence Interval

${ }^{5}$ Daily intake of breakfast (yes, no)

${ }^{6} \mathrm{TV}$ viewing $(0-2 \mathrm{~h} / \mathrm{d}$ or lees, $>2 \mathrm{~h} / \mathrm{d})$

${ }^{7}$ Parents obesity: At least one of parents is obese (yes, no)

${ }^{8}$ Daily physical activity (yes, no)

${ }^{9}$ Pocket money: the amount of Dh (Dirham Emirate) that each student brings daily and buy foods from the school canteen, $1 \$=3.678 \mathrm{Dh}(0-3 \mathrm{Dh} / \mathrm{d},>3 \mathrm{Dh} / \mathrm{d})$ 


\section{Discussion}

Overweight and obesity are considered as an 'epidemic' in many countries in the World, including developed and developing countries. Prevalence of obesity and overweight varies greatly with age groups, gender and socioeconomic status. It has been shown that the epidemiological transition seen in the developing countries as a result of urbanization, migration, new eating habits, and recent affluence are considered as some of the factors involved in the development of obesity and overweight. In the present study, the prevalence of the risk of overweight and overweight was found to be $11.1 \%$ and $15.8 \%$, respectively among female primary school children. The prevalence of overweight reported in our study seemed to be higher than that reported by Al Haddad et al. (2000) and Badrinath et al. (2000) in the UAE and in $\mathrm{Al}$ Ain respectively. In the first study, Al Haddad et al. (2000) reported a prevalence of $8 \%$ of obesity among UAE school children (boys and girls). Badrinath et al. (2000) found that 10.4\% of children (boys and girls) aged between 2 and 15 years were classified as obese. Other recent studies in the Arabian Gulf countries reported a high prevalence of overweight and obesity. In Saudi Arabia, El Hazmi and Warsy (2002) noted that the overall prevalence of overweight and obesity among girls aged between $1-18$ years was $12.7 \%$ and $6.7 \%$, respectively. They noted a high variability in the prevalence between provinces and age groups. Eastern province and the age group (6-9 years) had the highest prevalence of overweight and obesity.

Paediatric overweight is caused by a complex interplay of both genetic and environmental factors. The extent to which these factors contribute to overweight within a population has not been established and it is likely that the identity and relative contribution of risk factors differ among individuals. Socioeconomic status (SES) is a useful indicator of a constellation of environmental and familial influences potentially related to overweight. There is a controversial relationship between social factors and overweight in the literature. Whereas among adults an inverse relationship between SES and overweight is found frequently, studies of children find a weaker and less consistent relationship (Melnik et al., 1998). A number of studies have shown an inverse relationship between the level of parental education and overweight in children (Garn et al., 1975; Kemper et al., 1999). We have used parental education and occupation as a measure of SES. Our results suggest that there is no relationship between SES and prevalence of obesity among female school children in Al Ain. In contrast to this finding recent studies suggest that low SES may be a risk factor for obesity among children as young as preschool age (Gerald et al., 1994; Sherman et al., 1995; Spiegelaere et al., 1998). The discrepancy between our study and other studies may be due to the fact that Al Ain city is a part of the rich oil producing country, where nationals enjoy a high per capita yearly income irrespective of education and occupation, as a result, SES groups are not distinctly defined.

Dietary habits are among the factors that are associated with overweight and obesity among both children and adults. In this study, we considered few dietary factors (breakfast intake, number of meals, and food consumption patterns) and these mostly concentrated on qualitative rather than quantitative indicators. We found that the prevalence of girls who skipped breakfast increased with age, and girls who took breakfast had less prevalence of obesity compared to those who skipped breakfast, and the difference was statistically significant. Links between eating pattern and overweight have also 
been reported. Reported associations of food groups with childhood overweight include: low intake of fruit and vegetables (Moore et al., 1995), high intake of fast foods and sweets (Muller et al., 1999; Robinson, 1999), and high intake of sugar-sweetened beverages such as soft drinks (Ludwig et al., 2001). It is estimated that only $30 \%$ of US children meet the goals set by the food guide pyramid for daily intake of grains, meats, fruits and vegetables. The same pattern was observed in our study. We found that $26 \%$ and $60 \%$ of children daily consumed soft drinks and chips respectively, while the consumption of fruits and vegetables (leafy vegetables) was $32 \%$ and $28 \%$ respectively. We did not find a significant association between daily consumption of different foods and overweight. We noted low prevalence of daily consumption of milk whether it is full or low fat milk. Several studies suggest that consumption of excessive soft drink or other sweetened beverages is related to pediatric overweight (Troiano et al., 2000; Ludwig et al., 2001; Matheson et al., 2004). It has been shown that for each additional serving of a sugar-sweetened beverage consumed daily over a $11 / 2$ year period among school-aged children, the risk of becoming overweight increased $60 \%$ after controlling for other confounding variables (Ludwig et al., 2001).

The multiple logistic regression analysis showed that breakfast intake, TV viewing, physical activity and parents obesity were significant associated factors with overweight after adjusting for age. Parents obesity is one of the most important risk factor for childhood obesity (Serdula et al., 1993; Lake et al., 1997; Whitaker et al., 1997; Guo and Chumlea, 1999). Whitaker et al. (1997) found that among young children (under 3 years of age) the strongest predictor of adulthood obesity was parental obesity status. The risk of becoming an obese adult increased 3-fold if one parent was obese and 13-fold if both parents were obese. In addition to confirming this relationship, Lake et al. (1997) also reported a stronger pattern of overweight tracking from childhood to adulthood among subjects with two obese parents. In agreement with these studies, the present study showed that overweight was significantly associated with parents' obesity. Using logistic regression analysis, Moussa et al. (1994) reported an association between obesity and family history of obesity among school children in Al Ain. Among environmental factors, physical activity, TV and media and dietary factors are the most important risk factors for overweight and obesity. Several studies suggest that sedentary behavior is common in a relevant portion of children today and it has been identified as a significant predictor of weight gain later in life. Low levels of physical activity have been related to increased childhood overweight (Moore et al., 1995; Takahashi et al., 1999; Garaulet et al., 2000; Crespo et al., 2001). In the longitudinal Framingham Children's Study, preschool children with low levels of physical activity gained substantially more subcutaneous fat than did more active children (Takahashi et al., 1999). Our results show that inactive girls were more likely to be obese compared to active girls. It is noted that in many schools, physical activity was cancelled from the curriculum. Low physical activity levels have been associated directly with TV viewing and inversely with time spent outdoors (Gortmaker et al., 1996). Television viewing has become a common activity among children in many countries and more than ninety percent of children live in a home with at least one TV set. We found that more than $90 \%$ of children spent at least $2 \mathrm{~h} / \mathrm{d}$ watching $\mathrm{TV}$. Time spent viewing TV has consistently been shown to be associated with overweight status (Gortmaker et al., 1996; Takahashi et al., 1999; Hanley et al., 2000). 
Gortmaker et al. (1996) reported that children who watched TV for more than $5 \mathrm{~h} / \mathrm{d}$ have a nearly 5 -fold increased risk of overweight compared with those who watched $0-2 \mathrm{~h}$. Our results showed a higher risk for overweight among children who watched TV for more than $2 \mathrm{~h} / \mathrm{d}$. Researchers have suggested two mechanisms by which television viewing contributes to overweight. These mechanisms are reduced energy expenditure from reduction in physical activity and /or increased dietary intake, either during viewing or as a result of food advertising (Maffeis et al., 1997; Crespo et al., 2001). We also found that $48.1 \%$ of children ate while watching $\mathrm{TV}$, the most consumed products during watching TV were candies, chips, and chocolates which are rich source of energy.

In conclusion, the present study documented a high prevalence of risk of overweight and overweight among female school children in Al-Ain. Studying overweight in childhood is important since identification of children who may become obese adults can facilitate early intervention and avoidance of the morbidity and mortality associated with adult obesity. For that, a multisectorial intervention should be established which considers the dietary intervention to modify food habits, education through mass media and encouraging habitual physical activity among primary school children in $\mathrm{Al}$ Ain city.

\section{Acknowledgement}

This research was supported by the Research Affairs of the UAE University under contract $\mathrm{N}^{\mathrm{o}}$ 01-04-6-11/03. Authors would like to thank the UAE Ministry of Health and the UAE Ministry of Education for facilitating access to schools. Grateful acknowledgement is also due for senior and graduate students who participated in data collection and data entry.

\section{References}

Al-Awadi, F. and E. K. Amine. 1989. Overweight and obesity in Kuwait. J. R. Soc. Health. 109:175-179.

Al Haddad, F., Y. Al-Nuaimi, B. B. Little and M. Thabit. 2000. Prevalence of obesity among school children in the United Arab Emirates. Amer. J. Human. Biol. 12:498-502.

Al Isa, A. N. 1999. Dietary and socio economic factors associated with obesity among Kuwaiti college men. Br. J. Nutr. 82:369-374.

Al- Mahroos, F. J. and K. A. Al-Roomi. 1999. Overweight and obesity in the Arabian Peninsula: an overview. J. R. Soc. Health. 119:251-253.

Al-Shammari, S. A., T. A. Khoja and M. Al-Maatouq. 1994. High prevalence of clinical obesity among Saudi females: a prospective cross-sectional study in the Riyadh region. J. Trop. Med. Hyg. 97:183-188.

Badrinath, P., Q. A. Al-Shboul, T. Zoubeidi, A. S. Gargoun, R. Gubash and O. E. El-Rufaie. 2000. Measuring the Health of the nation. United Arab Emirates Health and Life style Survey.

Coon, K. A., J. Goldberg, B. L. Rogers and K. L. Tucker. 2001. Relationships between use of television during meals and children's food consumption patterns. Pediatrics 107:167-176.

Crespo, C. J., E. Smit, R. P. Troiano, S. J. Bartlett, C. A. Macera and R. E. Anderson. 2001. Television watching, energy intake, and obesity in US children: results from the Third National Health and Nutrition 
Examination Survey. Arch. Pediatr. Adolesc. Med. 155:360-365.

Dietz, W. H. 1994. Critical periods in childhood for the development of obesity. Amer. J. Clin. Nutr. 59:955959.

El- Hazmi, M. A. F. and A. S. Warsy. 2002. A comparative study of prevalence of overweight and obesity in children in different provinces of Saudi Arabia. J. Trop. Pediatrics. 48:172-177.

El- Mugamer, I. T., A. S. Ali Zayat, M., M. Hossain and B. N. Pugh. 1995. Diabetes, obesity and hypertension in urban and rural people of Bedouin origin in the United Arab Emirates. J. Trop. Med. Hyg. 98:407-415.

Flegal, K. M., R. Wei and C. Ogden. 2002. Weight for stature compared with body mass index for age growth charts for the United States from the Centers for Diseases Control and Prevention. Amer. J. Clin. Nutr. 75:761-766.

Garaulet, M., A. Martinez., F. Victoria., F. Perez-Liamas., R. M. Ortega and S. Zamora. 2000. Differences in dietary intake and activity level between normal-weight and overweight or obese adolescents. J. Pediatr. Gastroenterol. Nut. 30:253258.

Garn, S. M., S. M. Bailey, P. E. Cole and I. T. T. Higgins. 1975. Level of education, level of income, and level of fatness in adults. Amer. J. Clin. Nutr. 30:721-727.

Gerald, L. B., A. Anderson, G. D. Johnson, C. Hoff and R. F. Trimm. 1994. Social class, social support and obesity risk in children. Child. Care. Health. Dev. 20:145-163.
Gortmaker, S. L., A. Must, A. M. Sobol, K. Peterson., G. A. Colditz and W. H. Dietz. 1996. Television viewing as a cause of increasing obesity among children in the United States, 19861990. Arch. Pediatr. Adolesc. Med. 150:356-362.

Guo, S. S. and W. C. Chumlea. 1999. Tracking of body mass index in children in relation to overweight in adulthood. Amer. J. Clin. Nutr. 70:145S-148S.

Hanley, A. J. G, S. B. Harris, J. Gittelsohn, T. M. Wolever, B. Saksvig and B. Zinman. 2000. Overweight among children and adolescents in Native Canadian community: prevalence and associated factors. Amer. J. Clin. Nutr. 71:693-700.

Kemper, H. C. G., G. B. Post, J. W. R. Twisk and W. van Mechelen. 1999. Lifestyle and obesity in adolescence and young adulthood: results from the Amsterdam Growth and Health Longitudinal study (AGAHLS). Int. J. Obes. Relat. Metab. Disord. 23:S34S40.

Kim, S., S. Moon and B. M. Popkin. 2000. The nutrition transition in South Korea. Amer. J. Clin. Nutr. 71:44-53.

Klesges, R. C., M. L. Shelton and L. M. Klesges. 1993. Effects of television viewing on metabolic rate: potential implications for childhood obesity. Pediatrics 91:281-286.

Lake, J. K., C. Power and T. Cole. 1997. Child to adult body mass index in the 1958 British birth cohort: association with parental obesity. Arch. Dis. Child. 77:376-381.

Ludwig, D. S., K. E. Peterson and S. L. Gortmaker. 2001. Relation between consumption of sugar -sweetened 
drinks and childhood obesity. Lancet. 357:505-508.

Maffeis, C., S. Provera., S. Filippi., G. Sidoti., S. Schena and L. Tato. 2000. Distribution of food intake as a risk factor for childhood obesity. Int. J. Obes. Relat. Metab. Disord. 24:75-80.

Maffeis, C., M. Zaffanello and Y. Schutz. 1997. Relationship between physical inactivity and adiposity in prepubertal boys. J. Pediatr. 131:288292.

Matheson, D. M., J. D. Killen, Y. Wang, A. Varady and T. N. Robinson. 2004. Children's food consumption during television viewing. Amer. J Clin Nutr. 79:1088-1094.

Mei, Z., L. M. Grummer-Strawn, A. Pietrobelli, A. Goulding, M. I. Goran and W. H. Dietz. 2002. Validity of body mass index compared with other body composition screening indexes for the assessment of body fatness in children and adolescents. Amer. J. Clin. Nutr. 75:978-985.

Melnik, T. A., A. C. Rhoades., K. R. Wales., C. Cowell. and W. S. Wolfe. 1998. Overweight school children in New York City: prevalence estimates and characteristics. Int. J. Obesity. 22:7-13.

Moore, L. L., U. S. D. T. Nguyen., K. J. Rothman., L. A. Cupples and R. C. Ellisun. 1995. Preschool physical activity level and change in body fatness in young children. Amer. J. Epidemiol. 142:982-988.

Moussa, M. A. A., M. B. Skaik, S. B. Selwanes, O. Y. Yaghy and S. A. Bin-Othman. 1994. Factors associated with obesity in school children. Int. J. Obesity. 18:513-515.
Muller, M. J., I. Koertringer, M. Mast, K. Languix and A. Frunch. 1999. Physical activity and diet in 5 to 7 year old children. Public. Health. Nutr. 2:443444.

Nguyen, V. T., D. E. Larson, R. K. Johnson and M. I. Goran. 1996. Fat intake and adiposity in children of lean and obese parents. Amer. J. Clin. Nutr. 63:507-513.

Obarzanek, E., G. Schreiber G., P. Crawford, S. Goldman, P. Barrier and M. Frederick. 1994. Energy intake and physical activity in relation to indexes of body fat: the National Heart, Lung, and Blood Institute Growth and Health Study. Amer. J. Clin. Nutr. 60:15-22.

Popkin, B. M. 2001. The nutrition transition and obesity in the developing world. J. Nutr. 131:871S-873S.

Power, C., J. K. Lake and T. J. Cole. 1997. Measurement and long term health risks of child and adolescent fatness. Int. J. Obes. Relat. Metab. Disord. 21:507-526.

Robinson, T. N. 1999. Reducing children's television viewing to prevent obesity: a randomized controlled trial. JAMERA. 282:1561-1567.

Rolland-Cachera, M. F., M. Deheeger and M. Guilloud-Bataille. 1987. Tracking the development of adiposity from one month of age to adulthood. Ann. For Annals Human. Biol. 14: 219-229.

Schonfeld-Warden, N. and C. H. Waeden. 1997. Pediatric obesity: an overview of etiology and treatment. Pediatr. Clin. North. Amer. 44:339-361.

Serdula, M. K., D. Ivery, R. J. Coates, D. S. Freedman, D. F. Williamson and T. Byers. 1993. Do obese children become obese adults?. Prev. Med. 22:167-177. 
Sherman, G. B., Y. Liao, M. Alexander, M. Kim and B. D. Kim. 1995. Family factors related to obesity in Mexican -American and Anglo preschool children. Family. Comm. Health. 22:29-36.

Spiegelaere, M. D., M. Dramaix and P. Hennart. 1998. Socioeconomic status and changes in body mass from 3 to 5 years. Arch. Dis. Child. 78:477-478.

Takahashi, E., K. Yoshido H. and H. Sugimori. 1999. Influence factors on the development of obesity in 3-yearold children based on the Toyama study. Prev. Med. 28:293-296.

Troiano, R. P., R. R. Briefel, M. D. Carroll and K. Bialostosky. 2000. Energy and fat intakes of children and adolescents in the United States: data from the National Health and
Nutrition Examination Survey. Amer. J. Clin. Nutr. 72:1343S-1353S.

Wang, Y., K. Ge and B. M. Popkin. 2000. Tracking of body mass index from childhood to adolescence: a 6-y followup study in China. Amer. J. Clin. Nutr. 72:1018-1024.

Whitaker, R. C., J. A. Wright, M. S. Pepe., K. D. Seidel and W. H. Dietz. 1997. Predicting obesity in young adulthood from childhood and parental obesity. N. Eng. J. Med. 337:869-873.

Wolf, A. M., S. L. Gortmaker, L. Cheung, H. M. Gray, D. B. Herzog and G. A. Colditz. 1993. Activity, inactivity and obesity: racial, ethnic and age differences among schoolgirls. Amer. J. Public. Health. 83:1625-1627. 